\title{
AN INVESTIGATION OF THE EFFECT OF BIOMIMETIC TUBERCLES ON A FLAT PLATE
}

\author{
Alessandro Marino* \\ Department of Naval Architecture, \\ Ocean \& Marine Engineering \\ University of Strathclyde \\ 100 Montrose Street \\ G4 0LZ Glasgow, Scotland \\ Email: alessandro.marino@strath.ac.uk
}

\author{
Mehmet Atlar \\ Department of Naval Architecture, \\ Ocean \& Marine Engineering \\ University of Strathclyde \\ 100 Montrose Street \\ G4 0LZ Glasgow, Scotland
}

\author{
Yigit K. Demirel \\ Department of Naval Architecture, \\ Ocean \& Marine Engineering \\ University of Strathclyde \\ 100 Montrose Street \\ G4 OLZ Glasgow, Scotland
}

\begin{abstract}
This paper describes the investigation, by means of Computational Fluid Dynamics (CFD), of the effect of biomimetic tubercles on the hydrodynamics of a fully submerged flat plate. The application of these tubercles takes inspiration from the features of the humpback whale (Megaptera Novaeangliae). These huge marine mammals are capable of quick and agile movements in the water, despite their bulky bodies. Researchers investigated the causes of this ability by studying some peculiar somatic characteristics of these animals, in particular the tubercles on the leading edge of their pectoral fins. These tubercles were applied in the form of sinusoidal perturbations of the leading edge of wing profiles and foils, and they proved to cause a positive effect on the overall performance.

The aim of this paper is to investigate another type of tubercles, which appear in the shape of bumps on the whales head. The effect of these tubercles has not been studied yet, and this paper presents a study on the fundamental phenomena they generate in the water flowing on the surface of a flat plate. The tubercles are modelled as axisymmetric sinusoidal bumps placed on the flat plate. Different combinations of these tubercles are studied, in order to assess what the effect of a single tubercle is, and how more tubercles interact when they are placed closed to each other, in different configurations (number of tubercles and relative position). In addition, a systematic study of the effect of
\end{abstract}

\footnotetext{
*Address all correspondence to this author.
}

a single row of tubercles spanning perpendicularly to the flow is carried out. The tubercles change systematically in amplitude and position along the plate.

One further objective of this paper is to investigate if an optimised application of the biomimetic tubercles can lead to a drag reduction for the flat plate. Preliminary simulations show that the rows of tubercles interact with the boundary layer by modifying the pressure distribution, velocity and direction of the flow. The tubercles appear to generate vortices that are similar to those created by sinusoidal tubercles on the leading edge of foils, which tend to thin the boundary layer. A change in the total drag of the plate with tubercle is also noticeable, which even decreases from the baseline (flat plate with no tubercles), at certain combinations of position and tubercle amplitude.

\section{NOMENCLATURE}

A Tubercle amplitude

B Plate breadth

$C_{f}$ Frictional coefficient

$C_{p}$ Pressure coefficient

GCI Grid Convergence Index

L Plate length

$\mathrm{R}$ Resistance

$r_{f}$ Plate radius of fillet 


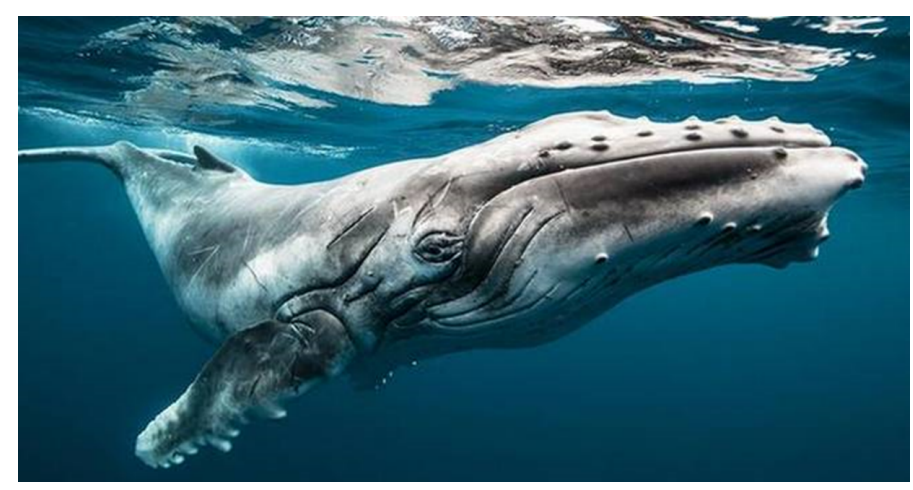

FIGURE 1. A MEGAPTERA NOVEANGLIAE

S Wet surface

SST Shear Stress Transport

$t$ Plate thickness

$\mathrm{U}$ Velocity in the $\mathrm{x}$ direction

VoF Volume of Fluid

$\mathrm{W}$ Velocity in the $\mathrm{z}$ direction

WSS Wall Shear Stress

$\lambda$ Tubercles wavelength

$\rho$ Water density

\section{INTRODUCTION}

The technology we benefit from every day often owes its progress to nature. Mimicking characteristics and behaviours of animals and plants can lead to the discovery of clever and efficient solutions to complex problems.

This is the case of biomimetic tubercles, which are representations of particular features of humpback whales (Megaptera Noveangliae).

As reported during scientific observations, as in [1], Humpback whales present different sets of tubercles on their pectoral fins and head. These characteristics are typical of these cetaceans, and they are not found in other species, as stated in [2]. The tubercles on pectoral fins were initially studied because they were believed to enhance the hydrodynamic performance and the ability of these whales to make sharp movements, despite their bulky bodies. The application of the technology derived from the observation of these protuberances is described in the next Section.

Fish et al. [3] report that humpback whales present very long pectoral fins (up to $33 \%$ of body length), which allow them to perform sharp and agile movements, despite the huge size of their body. The cross section of these flippers resembles a NACA 63-021 wing profile. The leading edge of the flipper has tipically nine to eleven tubercles, whose position is associated with that of joints and terminal phalanges of the manus, according to the observations of Cooper [4].
TABLE 1. DISTRIBUTION OF TUBERCLES ON THE HEAD OF HUMPBACK WHALES, ACCORDING TO [5]

\begin{tabular}{cll}
\hline & Adult & Calf \\
\hline Skull length & $3-4 \mathrm{~m}$ & $1.1 \mathrm{~m}$ \\
Skull width & $1.7-2.7 \mathrm{~m}$ & $0.64 \mathrm{~m}$ \\
$\begin{array}{c}\text { Mean intercluster } \\
\text { distance }\end{array}$ & $28 \mathrm{~cm}$ & $/$ \\
$\begin{array}{c}\text { StDev } \\
\text { Distance between }\end{array}$ & $12 \mathrm{~cm}$ & $/$ \\
tubercles within the same cluster & $>16 \mathrm{~cm}$ & $6-10.8 \mathrm{~cm}$ \\
Tubercle height & up to $6 \mathrm{~cm}$ & $0.7-2.5 \mathrm{~cm}$ \\
Tubercle basal circumference & $15.7-31.5 \mathrm{~cm}$ & $5.7-12 \mathrm{~cm}$ \\
\hline
\end{tabular}

Humpback whales also present numerous knobs (tubercles) on their head. According to [5], scientists agree that their function may well be sensorial, as they are highly innervated and develop early in the foetus. The tubercles inner structure suggest they serve the same function as Pacinian corpuscles in terrestrial mammals.

Mercado III [5] carried out a study on the spatial distribution of tubercles on adult and calf humpback whales. The distribution in adults was studied through the analysis of published and unpublished photographs, while as far as the calf is concerned, a model was studied, which is displayed at the Whalers Village Museum in Maui, Hawaii.

The findings in adults suggest remarkable differences among individuals, even though predictable spatial relationships were observed. In particular, tubercles in the middle crest of the upper jaw show a decreasing inter-tubercle distance closer to the jaw tip; the rest of the upper jaws show a rather regular pattern: the tubercles follow the edge of the jaw and their arrangement can be described as a double row or, as suggested by Mercado III [5], a single row if clusters, each with two to three tubercles. The lower jaw presents a less clear arrangement of tubercles, but some clusters could be identified. The observations on pictures of adults suggest that there is a huge variation on the tubercles distribution among individuals, despite the presence of patterns. Similar patterns were found on the calf model, even though the distances between clusters were bigger, but always in accordance with previous observations of other anatomists. Table 1 shows a summary of the findings of [5]. Fig. 2 shows a digital reconstruction of these findings. 

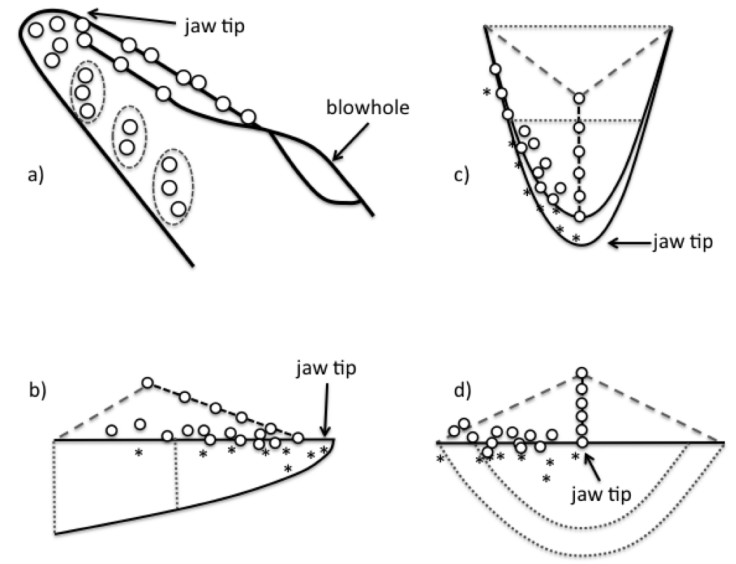

FIGURE 2. "(A) DIGITALLY TRACED IMAGE FROM A SCANNED PHOTOGRAPH OF AN ADULT HUMPBACK WHALE SHOWING HOW TUBERCLES ALONG THE UPPER JAW CAN BE VIEWED AS CLUSTERS; EACH CLUSTER IS ENCLOSED WITHIN A DOTTED ELLIPSE. NOTE THAT FOR THIS WHALE, UPPER JAW CLUSTERS ALIGN WITH MIDDLE CREST TUBERCLES. (B-D) THREE-DIMENSIONAL MATHEMATICAL MODEL OF TUBERCLE DISTRIBUTIONS MEASURED FROM A PHYSICAL MODEL OF A HUMPBACK WHALE CALF SHOWN FROM (B) THE SIDE, (C) OVERHEAD, AND (D) HEAD-ON PERSPECTIVES. EACH CIRCLE CORRESPONDS TO AN UPPER JAW TUBERCLE AND EACH ASTERISK CORRESPONDS TO A LOWER JAW TUBERCLE. PARABOLIC CURVES WERE FIT TO THE DIMENSIONS OF THE CALF HEAD (DOTTED LINES) AND THE DISTRIBUTION OF TUBERCLES (SOLID LINES). ALIGNMENT OF THE UPPER AND LOWER JAWS IS AN APPROXIMATION TO THE CLOSED MOUTH POSITION; THE MOUTH OF THE PHYSICAL CALF MODEL WAS OPEN" [5]

\section{Applications}

Fish et al. [3] report a summary of the application of leading edge tubercles on foils and wings, highlighting their positive effect on the overall performance, although the exact phenomena that occur to the flow are still uncertain [6]. Bolzon [6] explains there are several theories attempting to describe the tubercles mechanism, as the one proposed in [7], which compares the tubercles to vortex generators, induced flow, vortex lift, compartmentalisation theories; some studies assumed that the tubercles would delay stall due to a lower pressure gradient in the areas behind the tubercles, due to a lower thickness-to-chord ratio. None of the mentioned theories seems to fully explain the phenomena generated by the tubercles, but they all acknowledge that these protuberances produce streamwise contra-rotating vor-

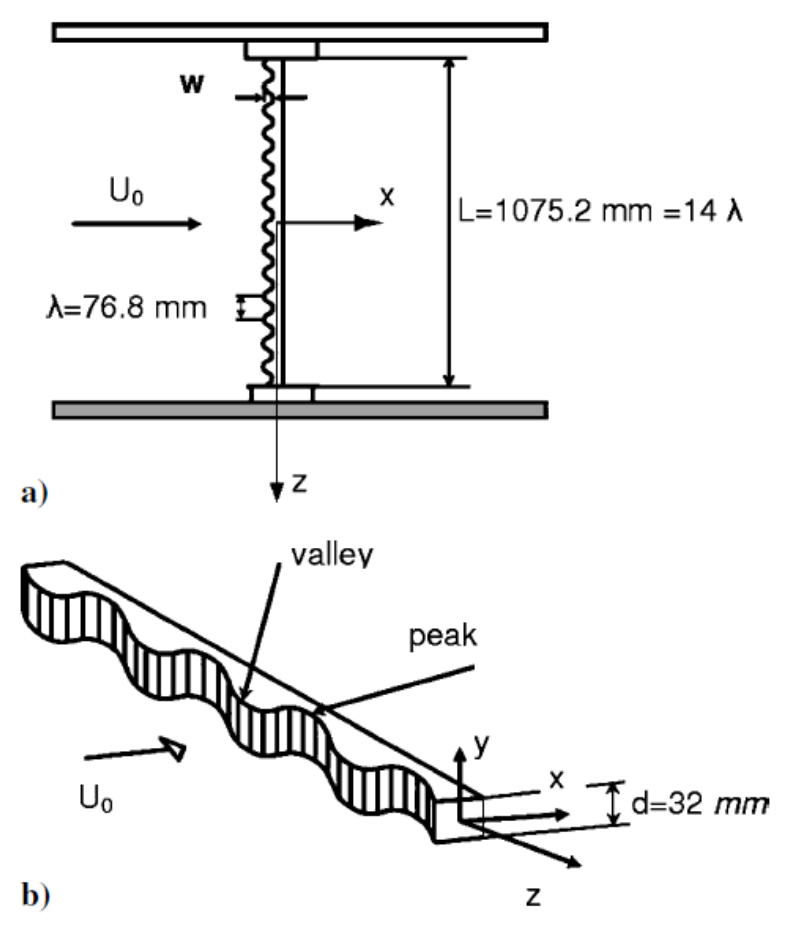

FIGURE 3. FLAT PLATE WITH SINUSOIDAL LEADING EDGE TUBERCLES, USED BY [8]

tices, which are believed to alter the boundary layer and the flow direction within. This would result in mixing higher momentum flow outside the boundary layer with lower momentum flow inside it, hence delaying the stall.

Several publications are available in literature about research on leading edge tubercles, on flat plates, and on foils or wing profiles. Dobre et al. [8] performed wind tunnel studies on the plates with sinusoidal tubercles on their leading edge, studying the effect of varying the sinusoidal amplitude. Their results show qualitative similarity between flows at low and high Reynolds number, pointing in the direction of similar flow characteristics. Figure 3 shows a schematic view of the tested plate. In the Figure, $\mathrm{L}$ is the length of the plate, $\mathrm{d}$ is the plate thickness, $\mathrm{w}$ is the sinusoidal amplitude and $\lambda$ is the spanwise wavelength.

The authors state that different configurations of leading edge tubercles can have an impact on different phenomena, such as wake decay or lift and drag fluctuations.

The fact that tubercles mix high and low momentum flow is hypothesised also in [9] and [10], where the authors investigated the effect of different patterns of perturbations (saw-tooth, semicircle, slot) on the leading edge of a flat plate in a low-speed wind tunnel. It was observed that streamwise contra-rotating vortices formed immediately after the troughs in each configuration, grew 


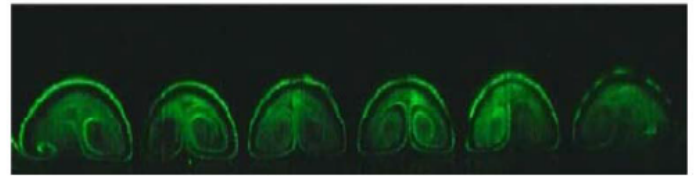

(a) Saw- tooth

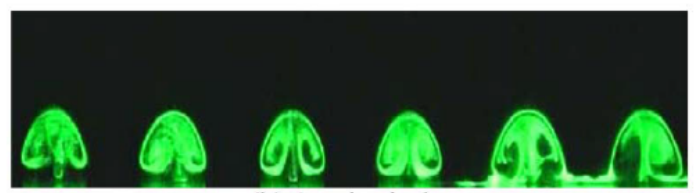

(b) Semi- circle

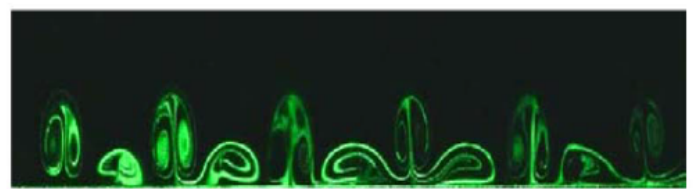

(c) Slot

FIGURE 4. MUSHROOM-LIKE PERTURBATIONS OBSERVED IN [9]

in a mushroom-like structure (Fig. 4), and propagated along the plate, eventually dissolving and causing turbulence. This phenomenon is caused by the mixing of the low and high momentum fluid.

The application of biomimetic tubercles has a remarkable impact also on marine technology. Several studies were performed on hydrofoils, such as rudders or tidal turbines. Weber et al. [11] carried out an experimental campaign on the effect of sinusoidal tubercles on lift, drag and cavitation onset on a rudder; the model was tested in a water channel. The experiments showed that adding tubercles to the leading edge of the tested rudder induces an earlier occurrence of stall, but with a higher lift coefficient maintained in the post-stall region. No drag penalty was recorded at low Reynolds numbers, but a higher drag coefficient was found at high Reynolds numbers; nevertheless, the tubercled rudder showed that, while the drag increased after stall, the lift remained almost constant, unlike the case of a regular rudder, where the lift has a drastic drop in the stall region. The tubercled rudder showed a better efficiency than the smooth one for Reynolds numbers below $7.1 \times 10^{5}$. Cavitation onset was observed at lower angles of attack and higher cavitation numbers, but it was localised in the areas between tubercles. This was also confirmed by Shi et al. [12], who also found that tubercled tidal turbine blades underwent cavitation earlier, but the misty type cloud cavitation was confined to the areas between the tubercles. The effect of leading edge tubercles on the performance of tidal turbine blades was extensively studied by several researchers, as in [12-17].

Grueber et al. [17] carried out towing tank tests on a set of tidal

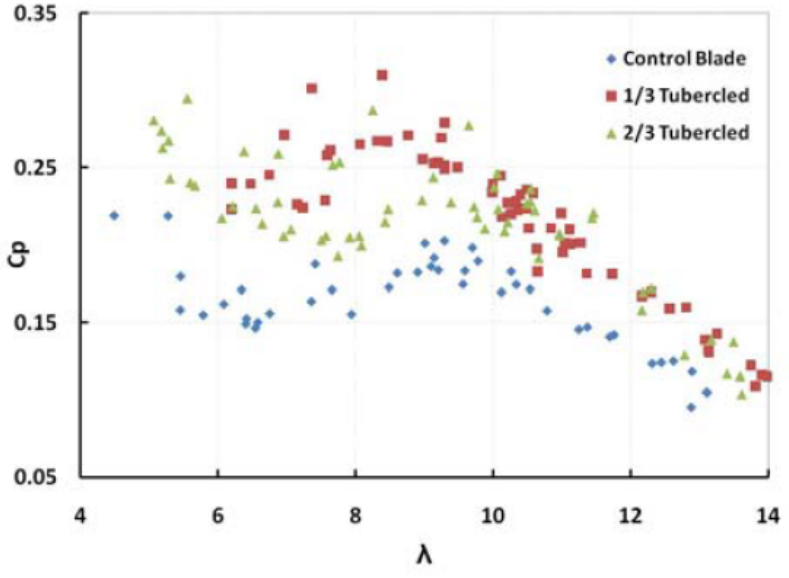

FIGURE 5. ROTOR POWER COEFFICIENT VS TIP SPEED RATIO, OBSERVED IN [17]

turbine blades, in order to quantify the effect of leading edge tubercles on the performance. Three different blades were tested: a reference blade with no tubercle coverage, and two blades with $1 / 3$ and 2/3 span coverage, respectively. Also Shi et al. [14] tested different a tidal turbine blade model with different coverage of tubercles and observed that the configuration where the tubercles are only on 1/4 of the blade's span, at its tip, is the best performing one. The lift-to-drag ratio is increased over a wider range of angles of attack and its peak value is also increased by more than $10 \%$. The experiments conducted by Grueber et al. [17] proved that tubercles improve the performance of the tidal turbine, as the extracted power for the 'tubercled' designs was always higher than that of the reference design (up to 85\%). This is shown in Fig. 5, which plots the rotor power coefficient $C_{p}$ versus the tip speed velocity ratio $\lambda$. It is clear that the tubercled blades perform better than the base design, as they provide more power at the same speed.

It is explained that the improvement is believed to be due to the tubercles reducing flow separation and inhibiting stall. The reduction in flow separation was also observed in [15] and [18], where numerical simulations and Particle Image Velocimetry (PIV) measurements were performed, and it was detected that the flow is more attached to the blades of a tidal turbine, due to the action of leading edge tubercles (Fig. 6). It was found that the contra-rotating vortices produced by the tubercles transmit more energy into the flow and reduce the separation, at the cost of slightly increasing the drag. The biomimetic tubercles produce a higher induction factor, hence a lower velocity in the wake field, which result in higher power and thrust coefficients. A higher power was also measured in [16] at lower Tip Speed Ratios (TSRs), with respect to a tidal turbine with no tubercles. 


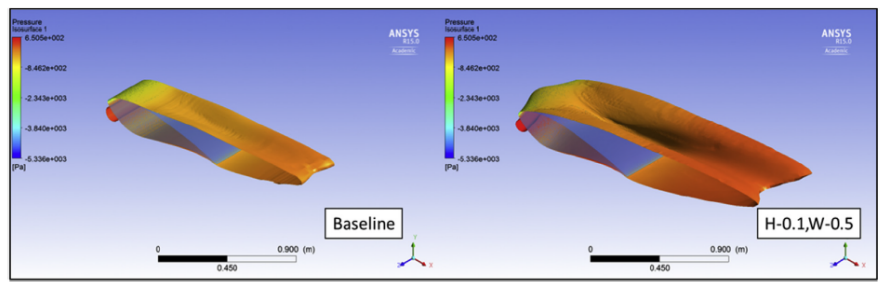

FIGURE 6. REDUCTION IN FLOW SEPARATION OBSERVED IN [14]

It was also observed that the tubercles improve the starting performance of the device, by reducing the cut-in velocity.

\section{Motivations}

Extensive research has been carried out on the effect of leading edge biomimetic tubercles on flat plates, and foils and wing profiles, highlighting the positive influence of these protuberances to the overall performance, despite a slight increase in the drag of these objects, due to more extensive energy exchange with the fluid.

The tubercles on the head of humpback whales, though, have not been object of investigation from a hydrodynamic point of view, although scientists published descriptions of their distribution and function on the head of these mammals. Mercado III [5] suggested that they could have a tactile function. Although their position on the head of the animals may also suggest that their interaction with the fluid is optimal when the flow is laminar, the flow around a ship, or another marine structure, is mostly turbulent. Hence, the present study is focused on the application of tubercles in a fully turbulent flow.

To the author's best knowledge, no studies have been carried out on the effect of these particular tubercles on the hydrodynamics of a marine structure, either a simple submerged flat plate or a ship hull.

\section{METHODOLOGY}

This section explains the approach and the setup of the CFD simulations used for this investigation. The geometrical models and the simulations were built with the aid of pieces of commer-

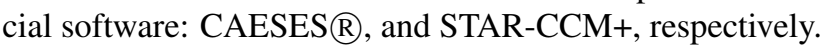

\section{Geometric model}

The tubercles are placed on a fully submerged flat plate, whose dimensions are summarised in Tab. 2.

For both the fundamental studies and the investigation on the effect of a full transverse row of tubercles, the tubercles are axisymmetric, with a sinusoidal profile. The amplitude (A) is
TABLE 2. DIMENSIONS OF THE FLAT PLATE USED IN THE SIMULATIONS

\begin{tabular}{cl}
\hline Dimension & \\
\hline $\mathrm{L}$ & $1.52 \mathrm{~m}$ \\
$\mathrm{~B}$ & $0.76 \mathrm{~m}$ \\
$\mathrm{t}$ & $0.0032 \mathrm{~m}$ \\
$r_{f}$ & $0.0016 \mathrm{~m}$ \\
\hline
\end{tabular}

changed throughout the second study, ranging from $2 \mathrm{~mm}$ to 5 $\mathrm{mm}$, in intervals of $0.5 \mathrm{~mm}$. The wavelength of the sinusoidal profile $\lambda$ is calculated with the aim of covering the whole breadth of the plate with a full row of ten tubercles, with a spacing of $2 \mathrm{~mm}$ between adjacent ones. Hence, in all cases $\lambda$ equals to $74 \mathrm{~mm}$.

Fundamentals. For the study on the fundamentals of the occurring phenomena, numerous configurations were modelled, in order to show the effect of a single tubercle (S), two tubercles aligned stream-wise (2-Al), three tubercles aligned stream-wise (3-Al), two tubercles aligned transversely to the stream direction (2-Tr), three tubercles aligned transversely to the stream direction (3-Tr). In configurations $S$ the peak of the tubercle is at $x=0.76 \mathrm{~m}$, i.e. exactly midlength of the plate; in configurations 2-Al and 3-Al, the peak of the upstream tubercle is in that position; finally, in configurations $2-\operatorname{Tr}$ and $3-\mathrm{Tr}$, all the tubercles are the same $\mathrm{x}$ position. These configurations are shown in Fig. 7.

Full row. The same plate is also modelled with a transverse row of adjacent tubercles. Its position varies: at the upstream edge, at mid-length, and at the downstream edge of the plate, as shown in Fig. 8. The sinusoidal tubercles are ten, and they cover the whole breadth of the plate. The amplitude of the profile varies from $2 \mathrm{~mm}$ to $5 \mathrm{~mm}$, with an interval of $0.5 \mathrm{~mm}$.

\section{CFD model}

All of the simulations are set so that the same environment is replicated. The plate with the tubercles is fully submerged, parallel to the water flow.

The Volume of Fluid (VoF) extends in the $\mathrm{x}$ direction (streamwise) from $-2 \mathrm{~L}$ to $1.6 \mathrm{~L}$; along the y direction (normal to the 


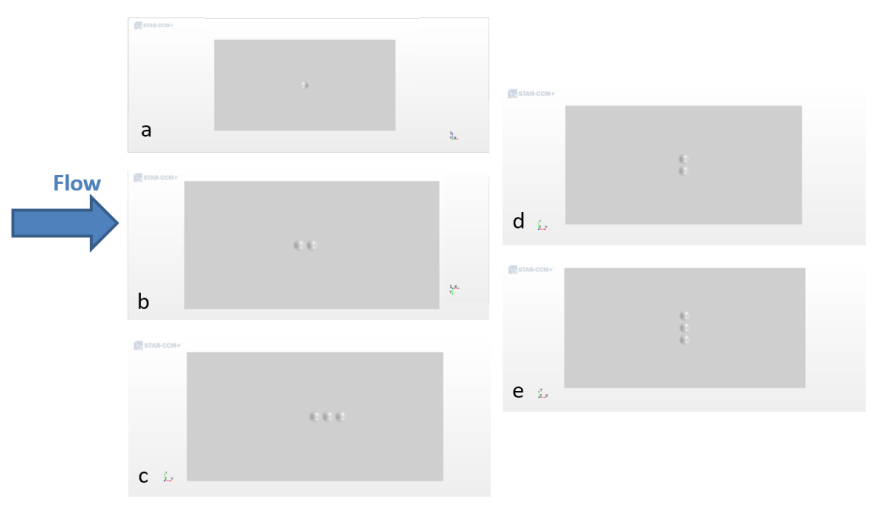

FIGURE 7. CONFIGURATIONS FOR FUNDAMENTAL STUDY: A) SINGLE TUBERCLE (S); B) TWO TUBERCLES ALIGNED STREAM-WISE (2-AL); C) THREE TUBERCLES ALIGNED STREAM-WISE (3-AL); D) TWO TUBERCLES ALIGNED TRANSVERSELY TO THE STREAM DIRECTION (2-TR); E) THREE TUBERCLES ALIGNED TRANSVERSELY TO THE STREAM DIRECTION (3-TR)

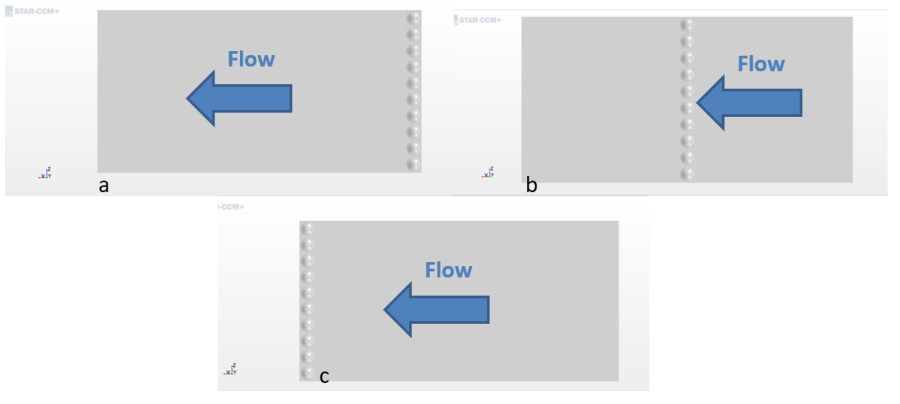

FIGURE 8. PLATE WITH A FULL TRANSVERSE ROW OF TUBERCLES AT: A) UPSTREAM EDGE, B) MIDLENGTH, C) DOWNSTREAM EDGE

plate), it extends until $0.6 \mathrm{~L}$; along the $\mathrm{z}$ direction, the VoF extends all over the breadth of the panel, but, in order to save computational time, in the cases where the full row is studied, it is cut by two symmetry planes, between which two tubercles are enclosed. In the other cases, the top and bottom walls are slip walls. In all cases, the inlet of the $\mathrm{VoF}$ is a velocity inlet, the outlet is a pressure outlet, while the far side is a no-slip wall (as if a towing tank test were simulated).

The turbulence model chosen for these simulation is $\kappa-\omega$ with Shear Stress Transport (SST), which is recommended for situations where the near wall effects need to be studied, as well as the those in the areas far way from the wall surfaces. This turbulence model is also suggested in cases where the separate flow region is to be predicted [19], although here the mesh is not solution adaptive.

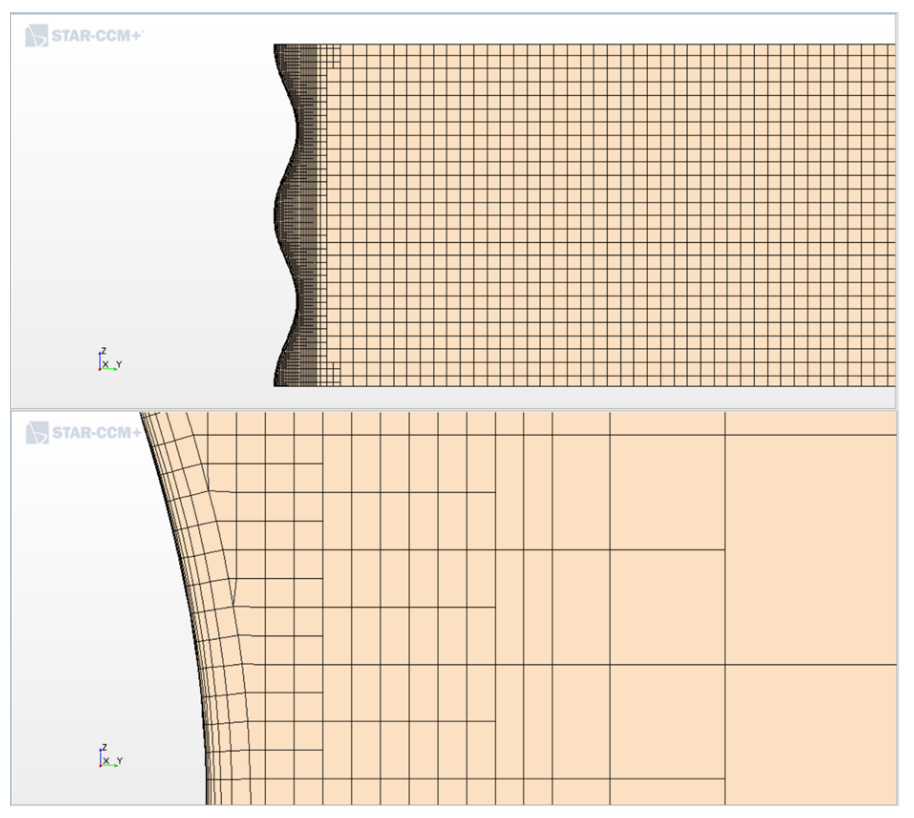

FIGURE 9. TOP: MESH ON A TRANSVERSE SECTION (Y-Z PLANE) OF THE PLATE WITH A FULL ROW OF TUBERCLES; BOTTOM: PARTICULAR OF THE SAME MESH, AT THE PEAK OF A TUBERCLE

Hexaedral mesh cells are used in all cases. The prism layer thickness is chosen so that $y^{+}$is always equal to 0.5 at the wall, and at least 100 in correspondence of the last layer, for each free stream velocity. The number of prism layers varies, in order to smooth the transition between one layer and the next one.

The total number of cells is slightly lower than 30 millions for the simulations on the fundamental phenomena, while it is reduced to about 14 millions for the studies on the full row of tubercles, as the VoF is cut by symmetry planes at the top and bottom.

Figure 9 shows an example of the mesh generated for the plate with a full row of tubercles.

\section{RESULTS}

This section describes the results of the simulations carried out during this investigation.

The CFD model is validated by comparing the resulting frictional resistance coefficient $C_{f}$ of a flat plate with the one obtained according to the ITTC 57 Model-Ship Correlation Line [20]. The difference always lies below $4.5 \%$.

\section{Grid convergence study}

A study on the dependence of the results on the grid size was carried out for the flat plate, the plate with a single tubercle (configuration $\mathrm{S}$ ), and the plate with a full transverse row of tubercles 
TABLE 3. GRID CONVERGENCE STUDY

\begin{tabular}{clll} 
& Flat plate & $\mathrm{S}$ & Full row \\
\hline$N_{f}$ & $7,376,976$ & $29,236,580$ & $13,358,873$ \\
$N_{m}$ & $3,749,329$ & $28,199,027$ & $6,626,175$ \\
$N_{c}$ & $3,239,916$ & $28,087,003$ & $5,749,343$ \\
$C_{f}$ & $2.81 \times 10^{-3}$ & $3.81 \times 10^{-3}$ & $2.6 \times 10^{-3}$ \\
$\left(\begin{array}{c}\text { (fine mesh) } \\
C_{f}\end{array}\right.$ & $2.81 \times 10^{-3}$ & $3.82 \times 10^{-3}$ & $2.6 \times 10^{-3}$ \\
(medium mesh) & & & \\
$C_{f}$ & $2.84 \times 10^{-3}$ & $3.82 \times 10^{-3}$ & $2.6 \times 10^{-3}$ \\
(coarse mesh) & & $0.12 \%$ & $0.01 \%$ \\
GCI & $0.000042 \%$ & & \\
\hline
\end{tabular}

at mid-length. The procedure followed in this paper is the one described in [21], based on [22].

Three sizes of mesh are chosen for each case, namely Fine, Medium, and Coarse. The corresponding number of cells $\left(N_{f}\right.$, $N_{m}, N_{c}$ ) is reported in Table 3, with the results for $C_{f}$ (chosen as the parameter $\phi$ ) and the Grid Convergence Index (GCI). $C_{f}$ is calculated at the top speed $(10 \mathrm{~m} / \mathrm{s})$ for the flat plate and full row cases, as a finer mesh is needed to achieve the same $y^{+}$values.

For accuracy of prediction, the fine mesh was then used in each simulation.

\section{Fundamentals}

The fundamental studies are carried out with a flow speed of $2 \mathrm{~m} / \mathrm{s}$, that corresponds to a Reynolds number of $3.41 \times 10^{6}$, calculated with the plate total length. The results show that the flow speed is increased in correspondence of the tubercles peaks. Despite the vortices generated behind the tubercles, the overall flow speed in the streamwise direction $(\mathrm{U})$ is higher than when calculated on the flat plate. When one, two or three tubercles are aligned in the streamwise direction (configurations $\mathrm{S}, 2-\mathrm{Al}$ and 3-Al, respectively), the flow velocity increases, particularly in correspondence of the third tubercle. The velocity profiles are displayed in Figs. 10 to 16.

Figure 10 shows a comparison of the velocity profiles (in streamwise direction) on the flat plate and on the peaks of the tubercles, in configurations $\mathrm{S}, 2-\mathrm{Al}$ and 3-Al. In all cases, the velocity profiles show values that are higher than the reference flat plate. It is to notice that in 2-Al configuration the flow velocity reaches the freestream value at a higher distance from the plate, and it shows lower values close to it. This phenomenon is observed in correspondence of the second tubercle (downstream) Fig. 11 shows that, despite the turbulence generated behind each tubercle, the velocity profiles at the troughs show the same tendency: the freestream velocity is higher than the reference case (flat plate). Also the velocity profiles at the bottom end of the

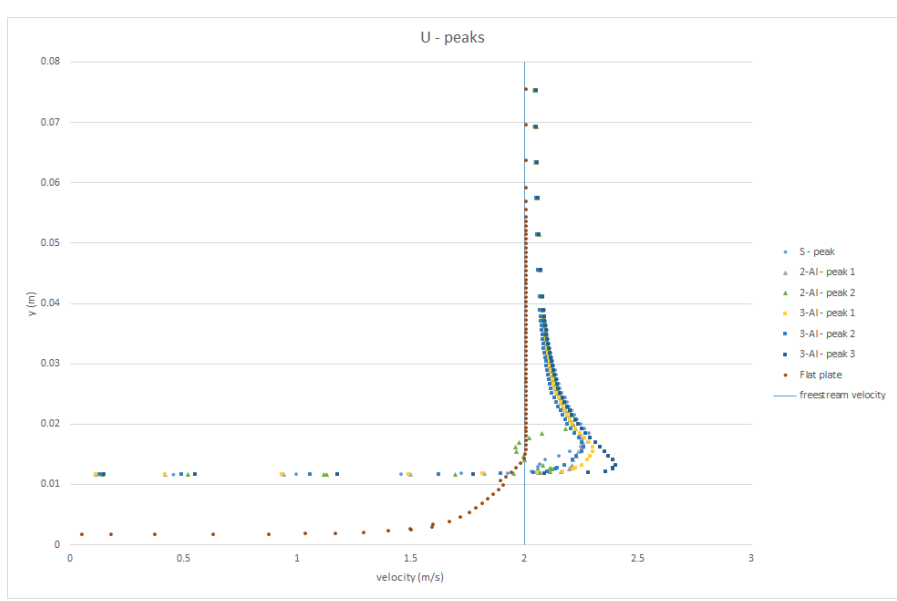

FIGURE 10. STREAMWISE VELOCITY PROFILES IN CORRESPONDENCE OF THE TUBERCLES' PEAKS. PEAKS 1, 2, 3 REPRESENT THE UPSTREAM, MID AND DOWNSTREAM TUBERCLE, RESPECTIVELY.

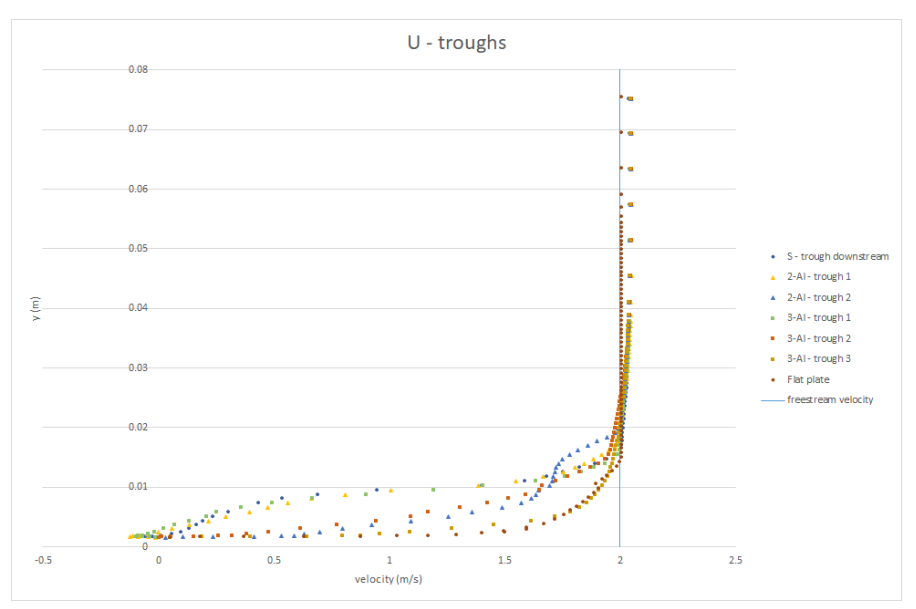

FIGURE 11. STREAMWISE VELOCITY PROFILES IN CORRESPONDENCE OF THE TROUGHS AFTER TUBERCLES. TROUGHS 1, 2, 3 REPRESENT THE TROUGHS AFTER THE UPSTREAM, MID AND DOWNSTREAM TUBERCLE, RESPECTIVELY.

tubercles, at the same $\mathrm{x}$ value of the peak, show the same behaviour (Fig. 12). The presence of turbulence at the troughs is well displayed in Fig. 13, where a colour map of the streamwise velocity is shown on a horizontal plane section cutting the tubercles in halves. This figure clearly shows how the presence of the third tubercle causes a reduction of the downstream boundary layer thickness, accelerating the flow even further.

The presence of tubercles aligned in the streamwise direction hence seems to increase the flow speed, while thinning the 


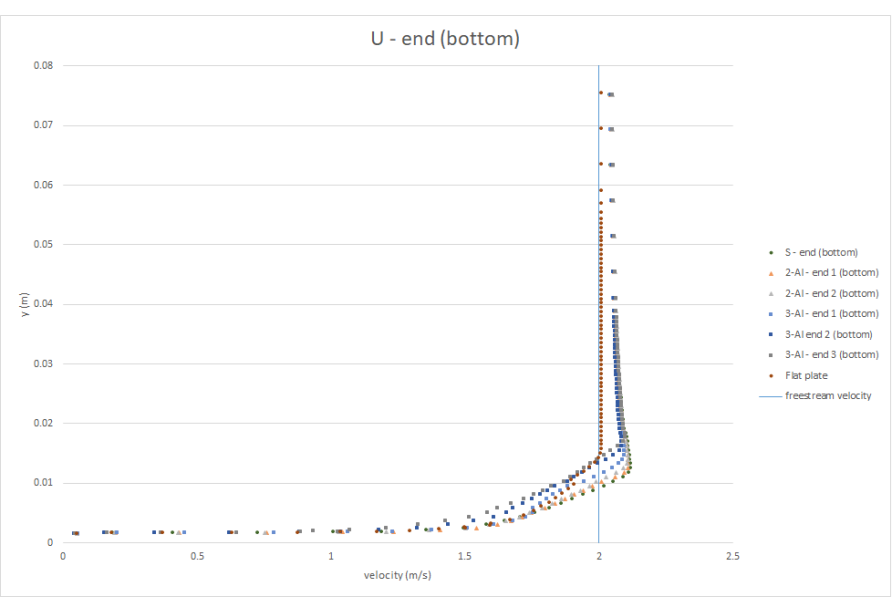

FIGURE 12. STREAMWISE VELOCITY PROFILES IN CORRESPONDENCE OF THE TUBERCLES' SIDES, AT THE SAME $X$ VALUE OF THE PEAKS. ENDS 1, 2, 3 REPRESENT THE UPSTREAM, MID AND DOWNSTREAM TUBERCLE, RESPECTIVELY.

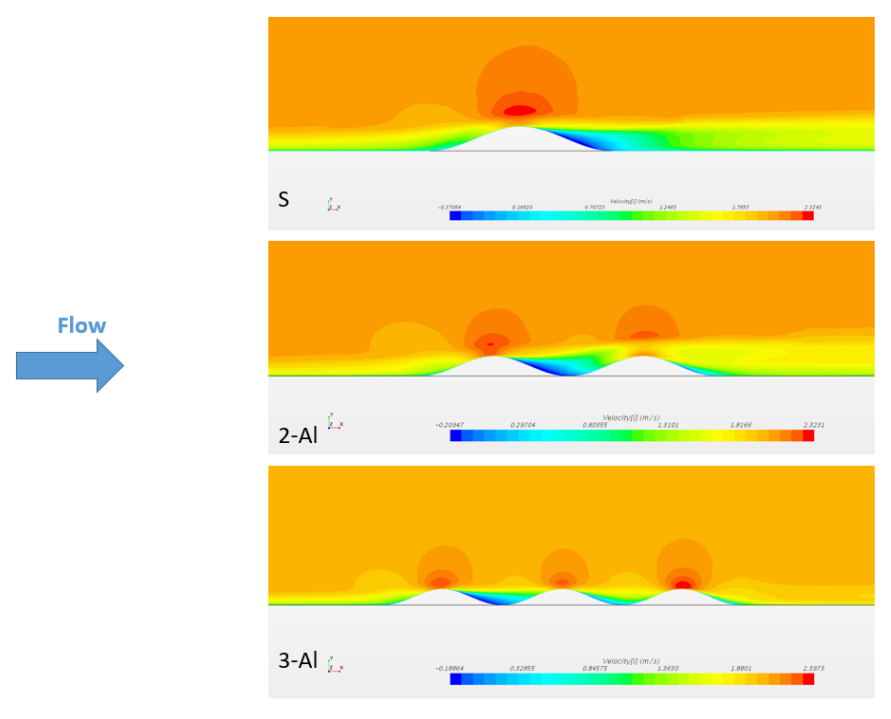

FIGURE 13. TOP VIEW (HORIZONTAL PLANE SECTION INTERSECTING THE PLATE AT TUBERCLES' PEAKS) STREAMWISE VELOCITY MAP IN CONFIGURATIONS S, 2-AL AND 3-AL.

boundary layer. With all the other conditions unvaried, the tubercles allow the flat plate to travel faster in the water, thus enhancing its performance.

The velocity in the spanwise direction (Figs.14 to 16), at the same positions, shows an oscillation before converging to $0 \mathrm{~m} / \mathrm{s}$ far off the plate, indicating that vortices are produced in that direction. This is confirmed by the values of the vorticity on the

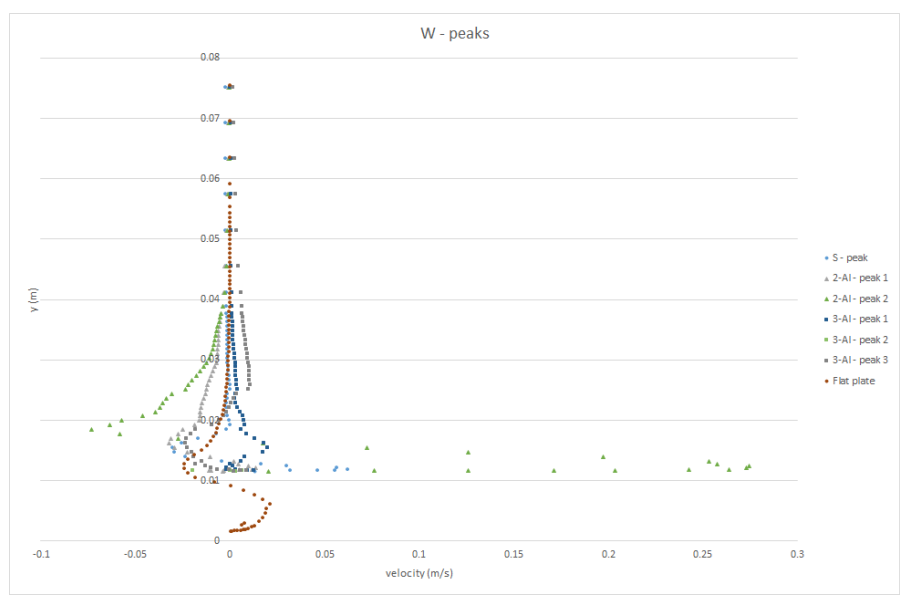

FIGURE 14. SPANWISE VELOCITY PROFILES IN CORRESPONDENCE OF THE TUBERCLES' PEAKS. PEAKS 1, 2, 3 REPRESENT THE UPSTREAM, MID AND DOWNSTREAM TUBERCLE, RESPECTIVELY.

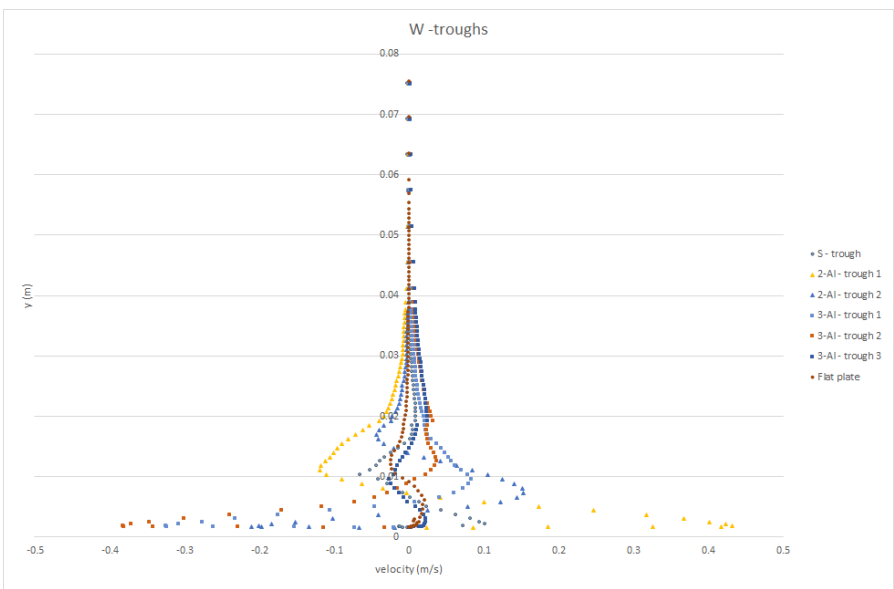

FIGURE 15. SPANWISE VELOCITY PROFILES IN CORRESPONDENCE OF THE TROUGHS AFTER TUBERCLES. TROUGHS 1, 2, 3 REPRESENT THE TROUGHS AFTER THE UPSTREAM, MID AND DOWNSTREAM TUBERCLE, RESPECTIVELY.

plates surface, as shown in Fig. 17. This Figure shows that areas with opposite vorticity are generated on the tubercles' surface, indicating the presence of vortices developping in the spanwise direction. This phenomenon suggests that contra-rotating vortices are generated, similarly to those observed in [9] and [14], which accelerate the flow, by reducing the boundary layer thickness.

Oscillations of the spanwise velocity are observed also with the flat plate, even though the velocity values are small (between -1\% 


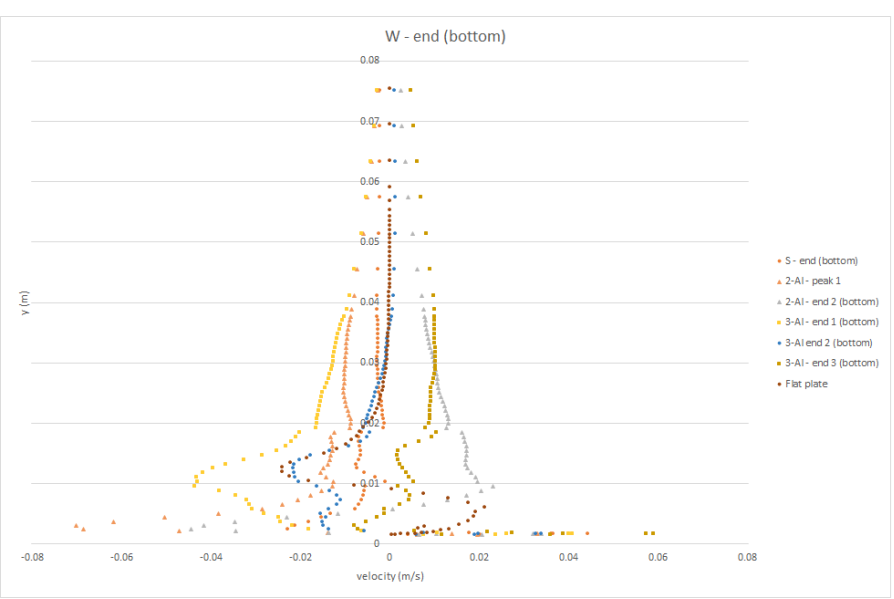

FIGURE 16. SPANWISE VELOCITY PROFILES IN CORRESPONDENCE OF THE TUBERCLES' SIDES, AT THE SAME $X$ VALUE OF THE PEAKS. ENDS 1, 2, 3 REPRESENT THE UPSTREAM, MID AND DOWNSTREAM TUBERCLE, RESPECTIVELY.

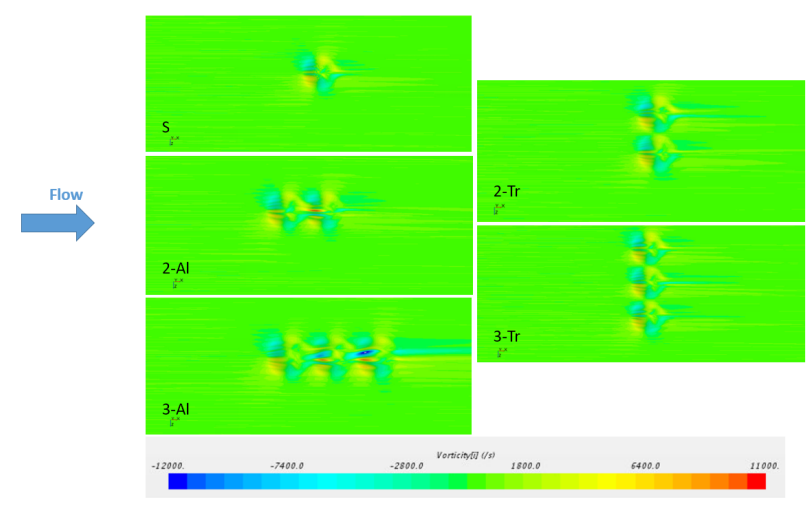

FIGURE 17. VORTICITY ON THE PLATE SURFACE, IN ALL CONFIGURATIONS.

and $+1 \%$ of the freestream velocity), and always ranging around a mean value of $0 \mathrm{~m} / \mathrm{s}$. These oscillations on a flat plate are acceptable, as per the unstable nature of the fully turbulent flow modelled in this study. When the tubercles are aligned transversely to the flow (configurations 2-Tr and 3-Tr), the streamwise velocity increases on the peaks. Again, vortices are generated after the tubercles and, despite this, the freestream velocity is higher than in the flat plate case. The velocity profiles shown in Figs 18 to 20 indicate that the flow is again accelerated, resulting in a higher freestream velocity. The spanwise velocity in Figs 21 to 23 shows again the presence of contra-rotating vortices, and this is confirmed by the vorticity values at the plates surface, as shown on the right-hand side of Fig. 17. The figure clearly shows

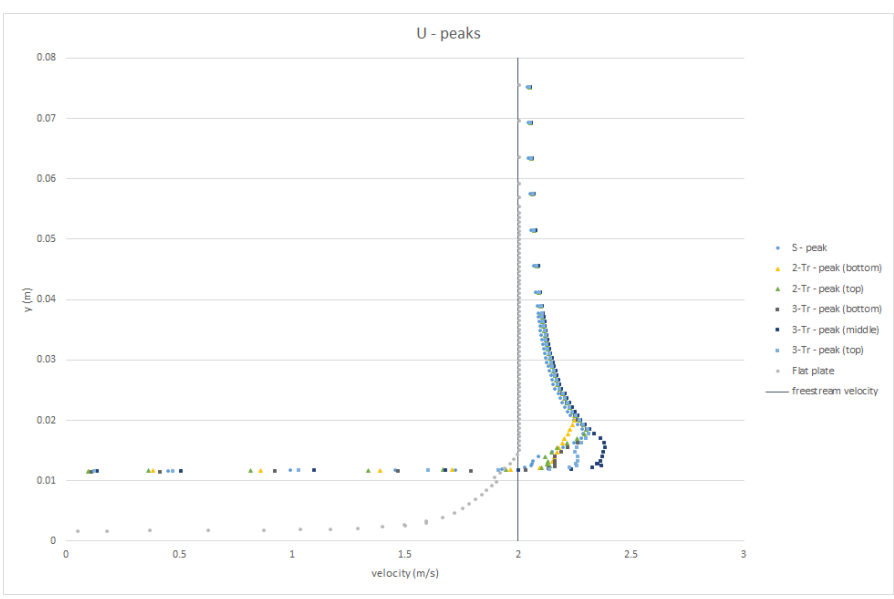

FIGURE 18. STREAMWISE VELOCITY PROFILES IN CORRESPONDENCE OF THE TUBERCLES' PEAKS.

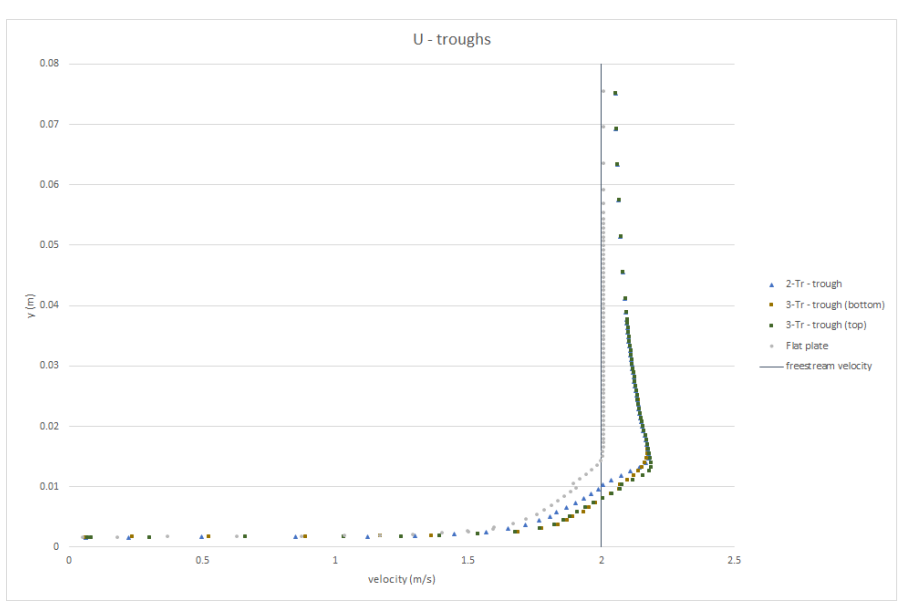

FIGURE 19. STREAMWISE VELOCITY PROFILES IN CORRESPONDENCE OF THE TROUGHS BETWEEN TUBERCLES.

that configurations 2-Tr and 3-Tr produce higher values of vorticity than 2-Al or 3-Al. This suggests that these arrangement of tubercles is more likely to produce vortices such as those observed in [9] and [14]. This is confirmed by the observation of the velocity profiles for the spanwise direction (Figs. 21 to 23). These figures show high oscillations at the tubercles peaks (Fig. 21) and downstream of them (Fig. 23); on the other hand, these oscillations are remarkably reduced at the troughs between tubercles (Fig. 22), where the contra-rotating vortices are expected to cancel out each other. In all the cases described above, the changes in the velocity values are confirmed by those in the pressure exerted by the flow on the plate's surface, as shown in Fig. 24 and in Figs. 25 to 27 . Figure 24 displays a colour map of the pressure distribution on the plate, with areas of higher pressure at the base- 


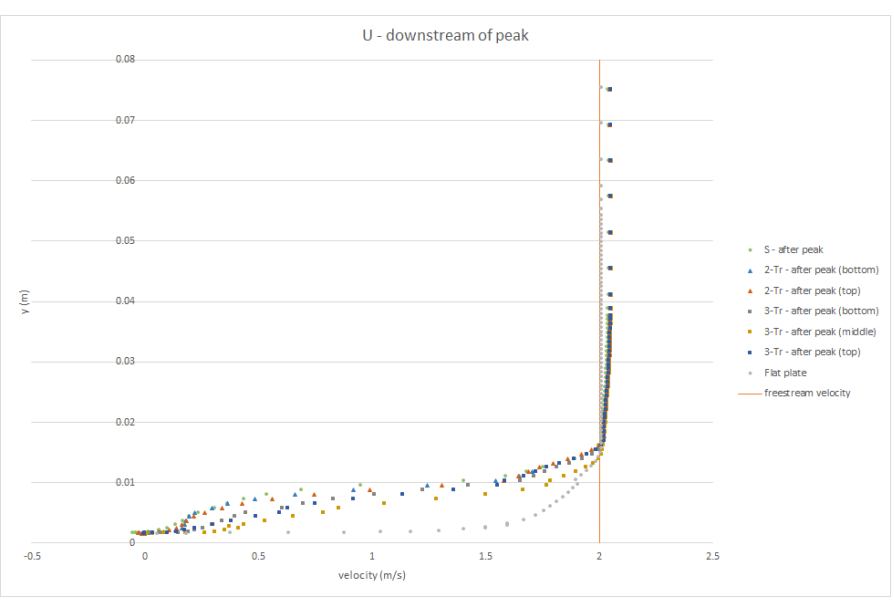

FIGURE 20. STREAMWISE VELOCITY PROFILES DOWNSTREAM OF THE TUBERCLES, IN CORRESPONDENCE OF THE PEAKS.

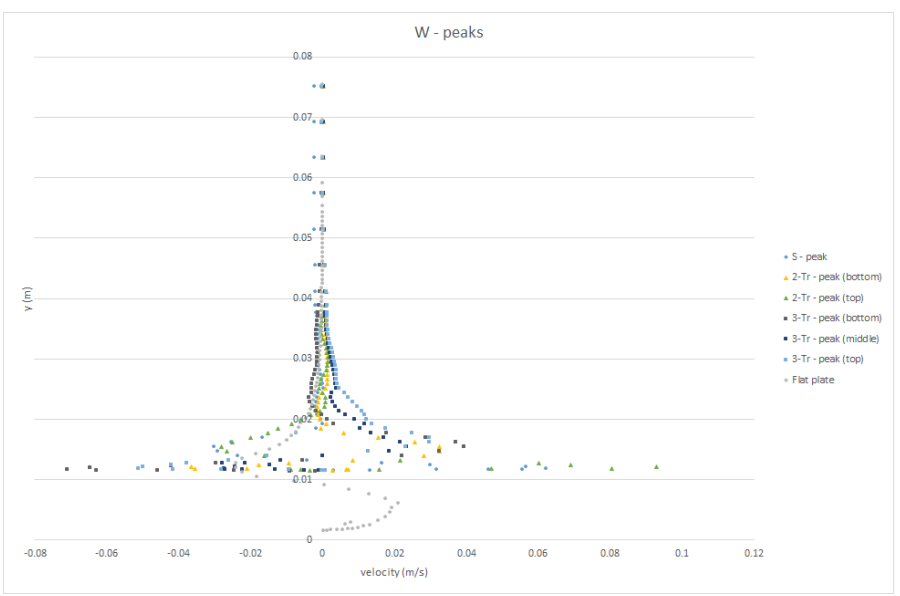

FIGURE 21. SPANWISE VELOCITY PROFILES IN CORRESPONDENCE OF THE TUBERCLES' PEAKS.

line of tubercles, and areas of lower pressure at the peaks, where the flow reaches its maximum streamwise velocity. This is confirmed by the graphs in Figs. 25 to 27, which show the pressure distribution on the plate with and without tubercles ("Flat plate" in the legend) along the the streamwise direction. It is interesting to observe the pattern of the wall shear stress (WSS) in the streamwise direction in the different configurations, as shown in Fig. 28. As the velocity varies along the surface in all different configurations, so does the WSS, which ranges from a value of -4.2 $\mathrm{Pa}$ to 25.6 $\mathrm{Pa}$. The WSS on the flat plate has a value between $5 \mathrm{~Pa}$ and $7 \mathrm{~Pa}$. The tubercles show the same WSS pattern in all configurations: minimum (and negative) values are achieved at the baseline, upstream of each tubercle or cluster of tubercles,

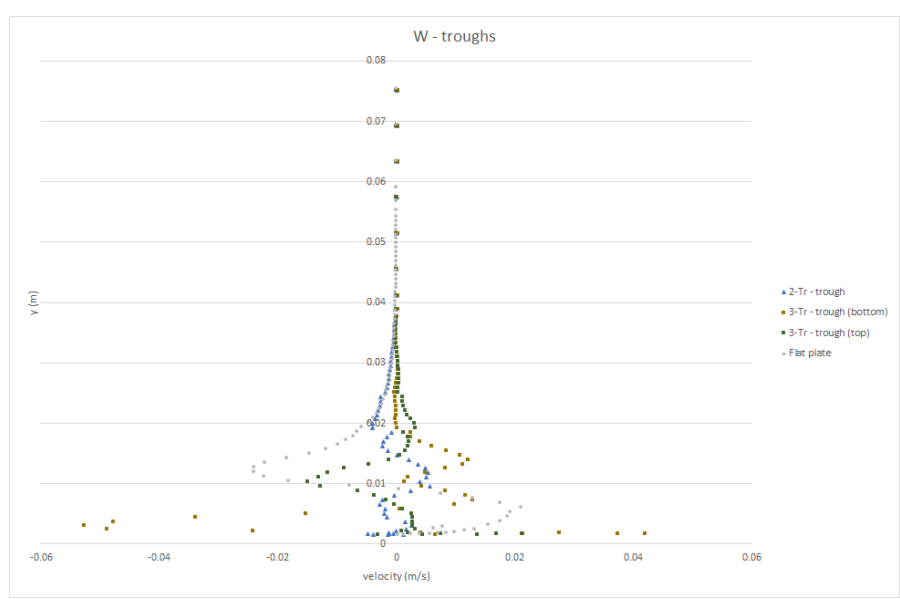

FIGURE 22. SPANWISE VELOCITY PROFILES IN CORRESPONDENCE OF THE TROUGHS BETWEEN TUBERCLES.

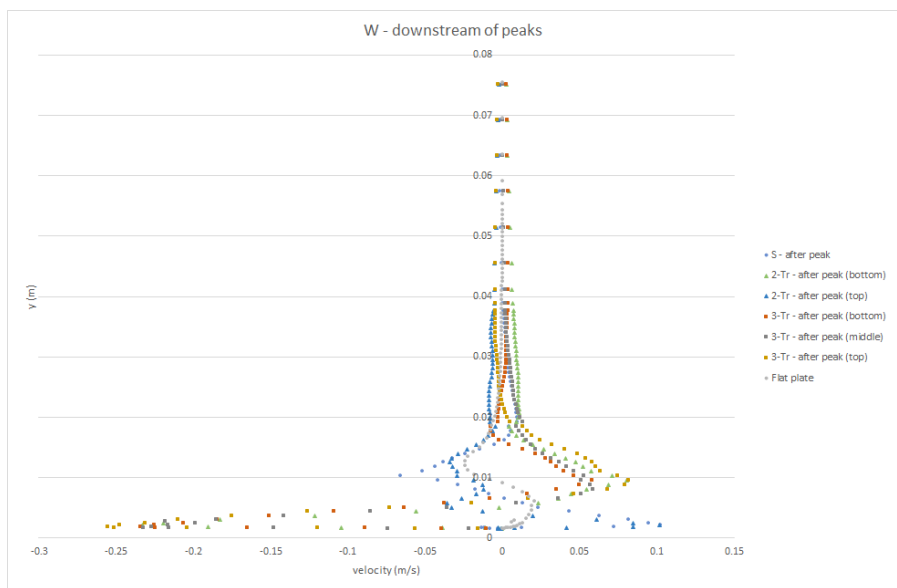

FIGURE 23. SPANWISE VELOCITY PROFILES DOWNSTREAM OF THE TUBERCLES, IN CORRESPONDENCE OF THE PEAKS.

and at the troughs between them. Maximum values are achieved reached at the peaks, where the flow undergoes maximum acceleration. The evaluation of WSS is important to assess a potential use of tubercles in foul prevention, and also the performance of 'tubercled' surfaces.

Finally, the resistance coefficient of the plate in all configurations is calculated, and it is compared to the $C_{f}$ of a flat plate, according to [20]. This choice is due to the fact that all the simulations are set for a fully submerged plate. The value of $C_{f}$ is calculated according to Eqn. (1):

$$
C_{f}=\frac{R}{\frac{1}{2} \rho U^{2} S}
$$




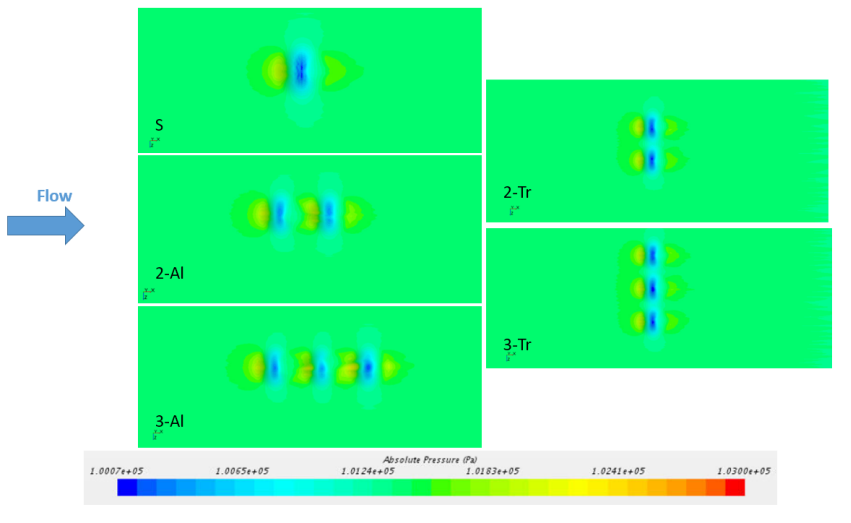

FIGURE 24. PRESSURE ON THE SURFACE OF THE PLATE, IN ALL CONFIGURATIONS.

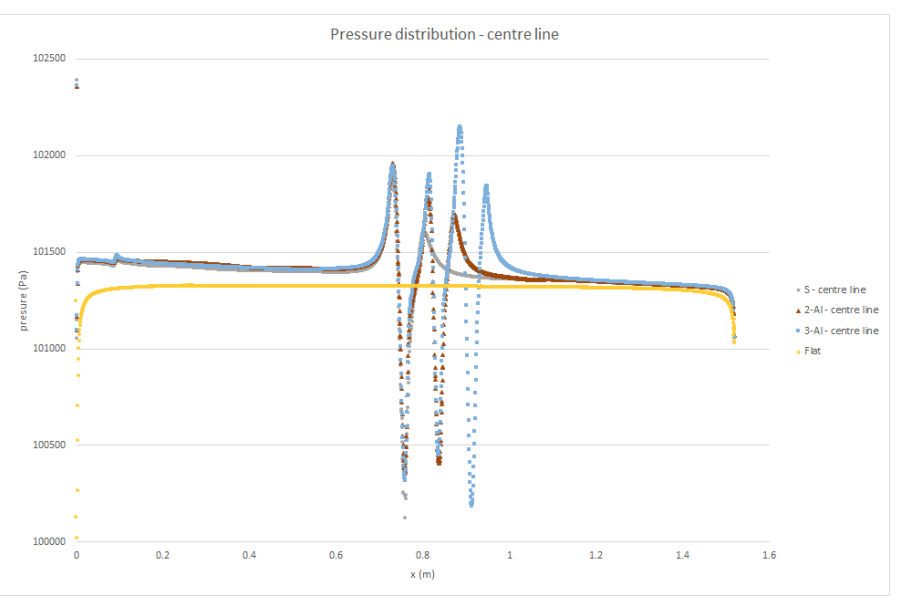

FIGURE 25. PRESSURE AT THE CENTRELINE OF THE PLATE, IN CONFIGURATIONS S, 2-AL, 3-AL.

Where $R$ is the total resistance, $\rho$ is the water density, $S$ is the total wet surface of the plate (and tubercles). Table 4 summarises the results. All configurations show an increase of the resistance coefficient, due to the presence of the tubercles in the boundary layer. This result is in accordance with boundary layer theory, nevertheless, although the overall $C_{f}$ increases, it can be seen (as explained above) that the presence of contra-rotating vortices thins the boundary layer thickness, showing a behaviour that is similar to that of leading edge tubercles on wing profiles, as described in the introductory part of this paper. This increases the freestream velocity even far off the plate's surface. These results encourage to a further investigation on the effect of tubercles.

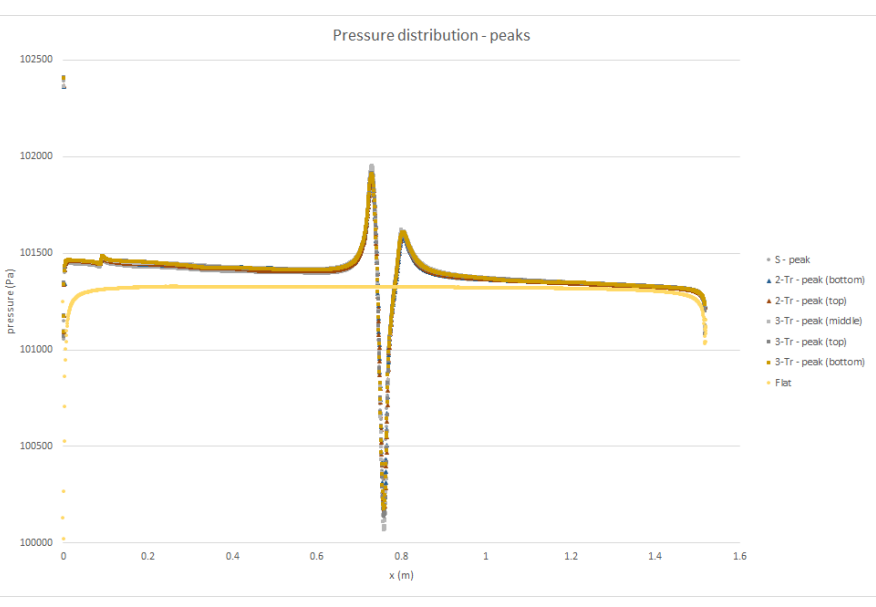

FIGURE 26. PRESSURE AT THE TUBERCLES' PEAKS, IN CONFIGURATIONS S, 2-TR, 3-TR.

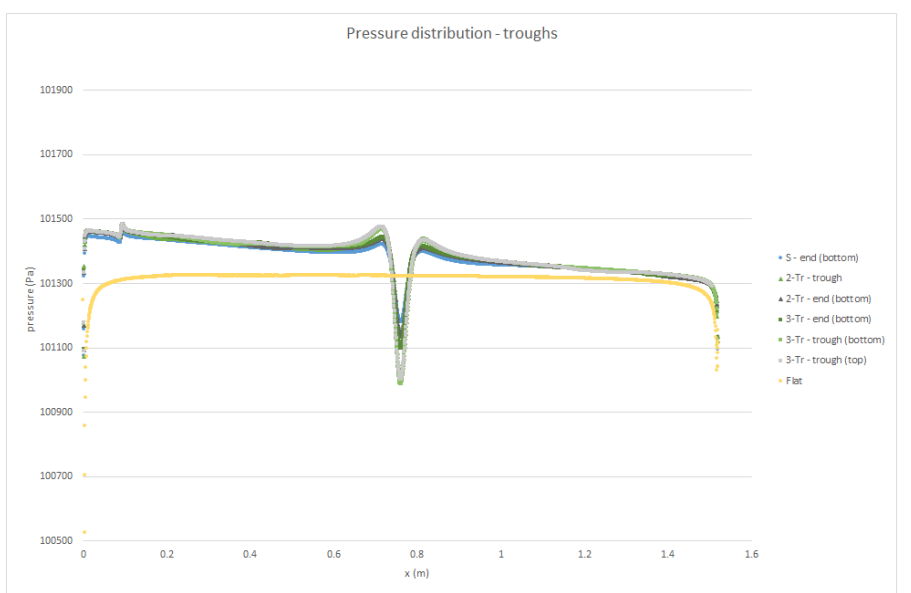

FIGURE 27. PRESSURE AT THE TROUGHS BETWEEN TUBERCLES, IN CONFIGURATIONS S, 2-TR, 3-TR.

\section{Full row}

The effect of the tubercles on the drag of a flat plate is at the same time investigated through a systematic study where the position of a full transverse (i.e. perpendicular to the flow) row of ten sinusoidal tubercles is varied, together with the amplitude (A) of the tubercles. Three positions are considered: upstream edge, midlength and downstream edge.

Firstly, the simulations are run at different velocities, with A unvaried: the flow speed ranges from $2 \mathrm{~m} / \mathrm{s}$ to $10 \mathrm{~m} / \mathrm{s}$ (i.e. Reynolds number from $3.41 \times 10^{6}$ to $1.71 \times 10^{7}$ ), with a step of $2 \mathrm{~m} / \mathrm{s}$. The resulting $C_{f}$ is reported in Fig. 29. All the configurations show a drag reduction at higher Reynolds numbers, and this leads to assert that the vortices created by the tubercles have a positive effect at higher speeds. It is important to notice that the midlength 


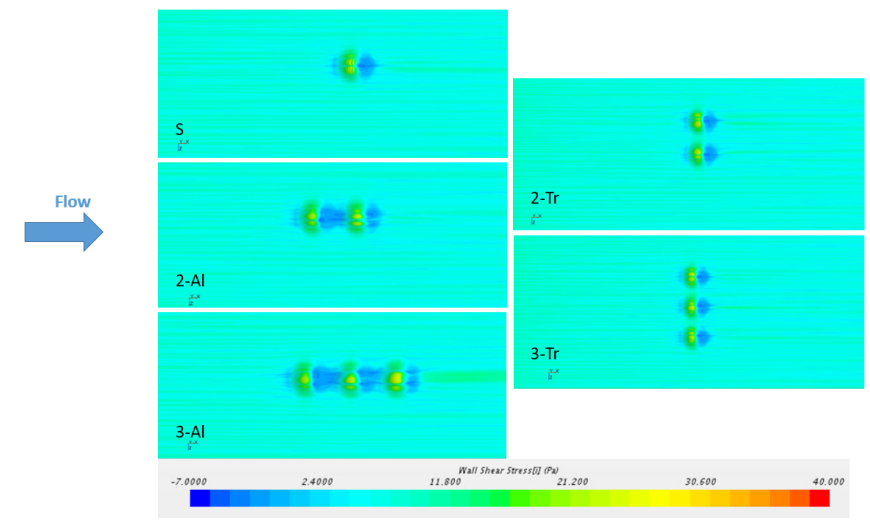

FIGURE 28. WALL SHEAR STRESS, IN ALL CONFIGURATIONS.

TABLE 4. $C_{F}$ OF PLATE WITH TUBERCLES, IN ALL CONFIGURATIONS.

\begin{tabular}{cl}
\hline Configuration & $C_{f}$ \\
\hline Flat plate & $3.80 \times 10^{-3}$ \\
$\mathrm{~S}$ & $3.81 \times 10^{-3}$ \\
$2-\mathrm{Al}$ & $3.86 \times 10^{-3}$ \\
$3-\mathrm{Al}$ & $3.89 \times 10^{-3}$ \\
$2-\mathrm{Tr}$ & $3.85 \times 10^{-3}$ \\
$3-\mathrm{Tr}$ & $3.87 \times 10^{-3}$ \\
\hline
\end{tabular}

configuration shows a decreased $C_{f}$ at all speeds. This suggests the position of the tubercles along the plate, associated with the boundary layer thickness, is critical in terms drag reduction, and this should be object of further investigation.

As already noted for the fundamental study, also with the full row of tubercles the velocity profile is remarkably affected by the presence of tubercles. As shown in Figs. 30 and 31, the flows undergoes an accelerations in correspondence of the tubercles, both on the peak and in the troughs, although the presence if the peaks causes a higher local acceleration. This behaviour happens in correspondence of changes in the pressure distribution along the length of the plate, which display the same trend already discussed for the fundamental study.

In all three full row configurations, the spanwise velocity at peaks and troughs features high oscillations before converging to $0 \mathrm{~m} / \mathrm{s}$ far off the plate. This confirms the trend already analysed, i.e. the presence of contra-rotating vortices developing along the plate. They seem to have an effect on the WSS, which affects

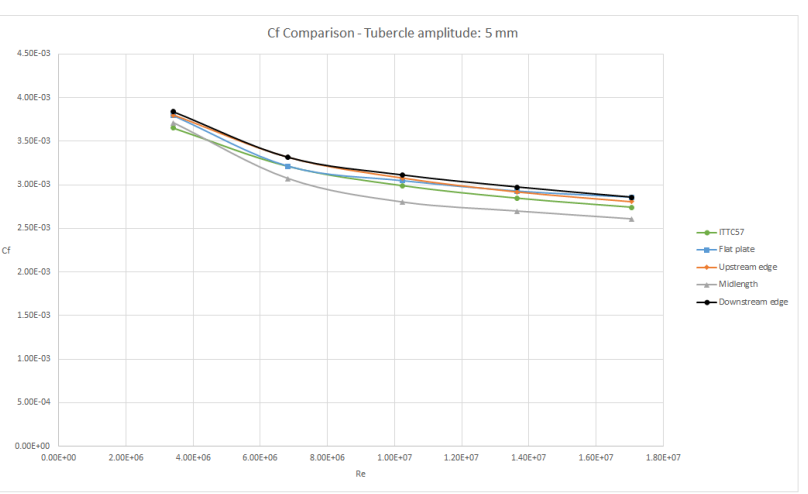

FIGURE 29. $C_{F}$ COMPARISON OF TRANSVERSE ROWS OF TEN TUBERCLES WITH A=5 MM AT UPSTREAM EDGE, MIDLENGTH AND DOWNSTREAM EDGE OF A FLAT PLATE

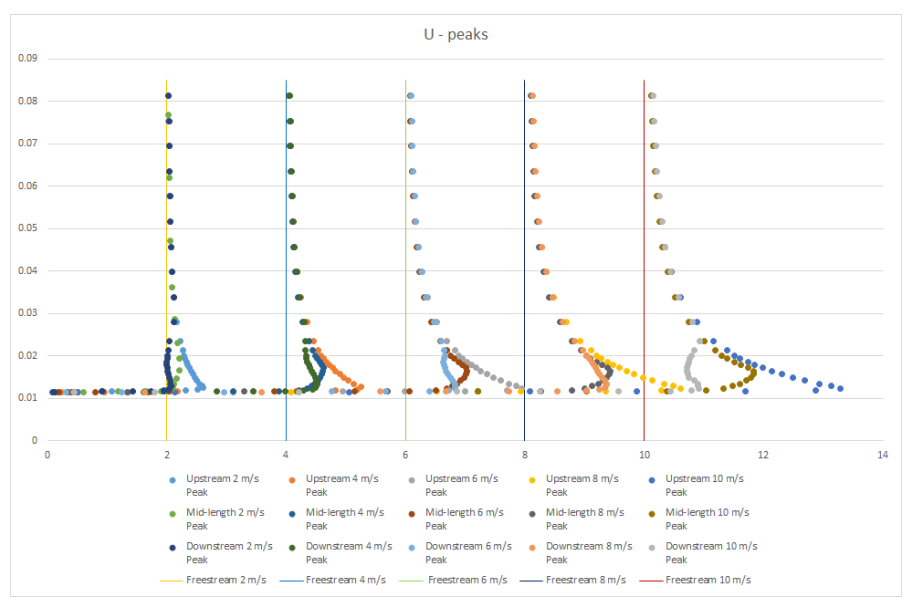

FIGURE 30. STREAMWISE VELOCITY PROFILES IN CORRESPONDENCE OF THE TUBERCLES' PEAKS, PLATE WITH FULL ROW OF TUBERCLES.

the frictional resistance. Figure 32 shows the difference of WSS between the reference flat plate and the three configurations of full rows of tubercles. Only the case at $10 \mathrm{~m} / \mathrm{s}$ is shown here, as it is the most significant, due to the results in terms of $C_{f}$ reduction. The figures shows that the areas with WSS smaller than that of the flat plate are large, hence this implies a smaller viscous resistance of the plate.

Since the row of tubercles seem to have a better effect at higher Reynolds numbers, a systematic study on the effect of the tubercle amplitude is carried out, where the flow velocity is kept constant at $10 \mathrm{~m} / \mathrm{s}$, i.e. Reynolds number of $1.71 \times 10^{7}$.

The amplitude varies from $2.5 \mathrm{~mm}$ to $5 \mathrm{~mm}$, with a step of 0.5 mm. The resulting $C_{f}$ values are displayed in Fig. 33. The friction coefficient tends to grow with $\mathrm{A}$, with the exception of the 


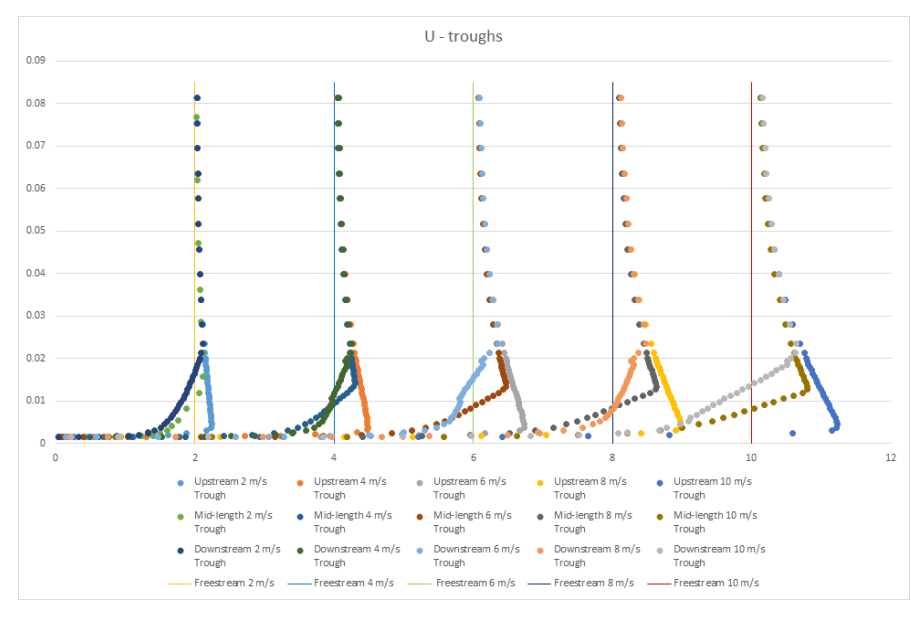

FIGURE 31. STREAMWISE VELOCITY PROFILES IN CORRESPONDENCE OF THE TROUGHS BETWEEN TUBERCLES, PLATE WITH FULL ROW OF TUBERCLES.

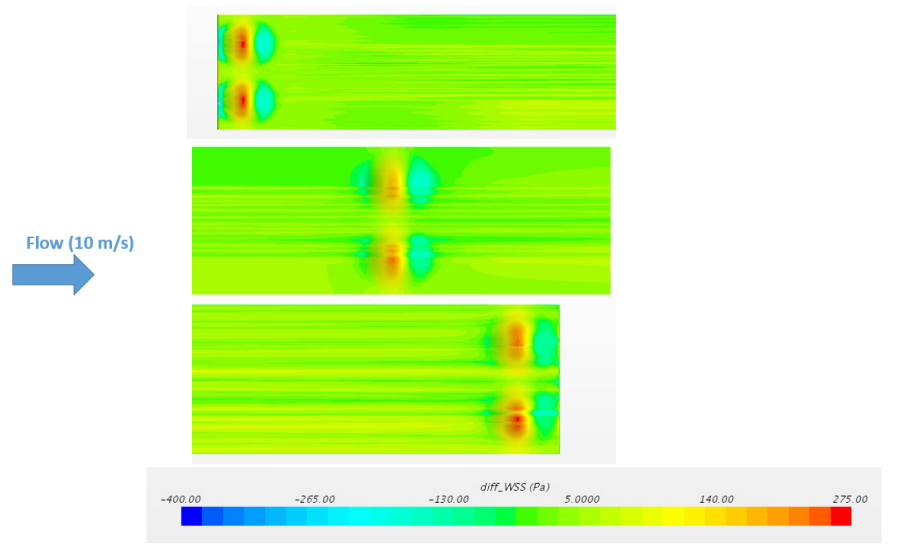

FIGURE 32. DIFFERENCE BETWEEN WSS OF FLAT PLATE AND THREE CONFIGURATIONS OF FULL ROWS OF TUBERCLES AT $10 \mathrm{M} / \mathrm{S}$.

downstream configuration, where it grows until $\mathrm{A}=4 \mathrm{~mm}$, then it decreases. The upstream configuration presents a peak at $\mathrm{A}=2.5$ $\mathrm{mm}$. This peak differs from the values corresponding to $A=2 \mathrm{~mm}$ and $A=3 \mathrm{~mm}$ of $5.8 \%$ and $5.3 \%$, respectively. This suggests, as stated above, that the interaction between the amplitude of the tubercles and the boundary layer thickness is critical to fully understand the hydrodynamic phenomena, and it opens the route for further investigation.

Regardless of the oscillations, all the values of $C_{f}$ are smaller than in the case of a normal flat panel ( $\mathrm{A}=0 \mathrm{~mm}$ in Fig. 33).

These results suggest that biomimetic tubercles, organised in transverse rows, can have a beneficial effect on the performance of a flat plate, that generates less drag at higher Reynolds num-

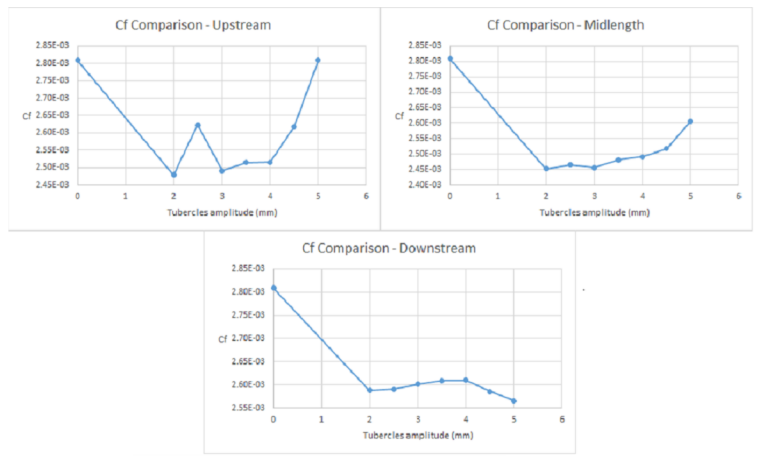

FIGURE 33. SYSTEMATIC $C_{F}$ COMPARISON OF TRANSVERSE ROWS OF TEN TUBERCLES WITH AMPLITUDE VARYING FROM 2.5 MM TO 5 MM AT UPSTREAM EDGE, MIDLENGTH AND DOWNSTREAM EDGE OF A FLAT PLATE

bers. This should be further investigate, by modifying the characteristics of the tubercles, and by carrying out experimental work as well.

\section{CONCLUSIONS}

This paper summarises the numerical simulations carried out to investigate the effect of biomimetic tubercles on a fully submerged flat plate. Different configurations and distributions of these sinusoidal tubercles are studied, in order to understand the fundamental phenomena occurring when the water flows around the plate with tubercles. Moreover, an optimisation study on the position and the tubercle amplitude of a full transverse row of tubercles is carried out, to assess the effect on the plate's frictional coefficient. It is found that the presence of the tubercles accelerates the flow, although it creates further vorticity around the plate. A full row of tubercles can, on the other hand, reduce the total drag of a flat plate, especially at higher Reynolds numbers. Biomimetic tubercles are a promising solution and can be applied to manipulate the flow over a flat plate and increase its performance. Further investigation, including physical experiments, can be done to understand the phenomena deeper.

\section{ACKNOWLEDGMENT}

Results were obtained using ARCHIE-WeSt High Performance Computer (www.archie-west.ac.uk).

\section{REFERENCES}

[1] Clapham, P. J., and Mead, J. G., 1999. "Megaptera novaeangliae". Mammalian Species(604), pp. 1-9. 
[2] Clapham, P. J., 2009. Humpback Whale: Megaptera novaeangliae A2 - Perrin, William F. Academic Press, London, pp. 582-585.

[3] Fish, F. E., Weber, P. W., Murray, M. M., and Laurens, E. H., 2011. "The tubercles on humpback whales' flippers: application of bio-inspired technology". Integrative and comparative biology., 51(1), p. 203.

[4] Cooper, L., 2007. "Evolution of hyperphalangy and digit reduction in the cetacean manus". The anatomical record : advances in integrative anatomy and evolutionary biology., 290(6), p. 654.

[5] Mercado III, E., 2014. "Tubercles: What sense is there?". Aquatic Mammals, 40(1), pp. 95-103.

[6] Bolzon, M. D., 2015. "Tubercles and their applications". Journal of aerospace engineering, 29(1), p. 04015013.

[7] Miklosovic, D., 2004. "Leading-edge tubercles delay stall on humpback whale (megaptera novaeangliae) flippers". Physics of fluids, 16(5), p. L39.

[8] Dobre, A., Hangan, H., and Vickery, B. J., 2006. "Wake control based on spanwise sinusoidal perturbations". AIAA Journal, 44(3), pp. 485-492.

[9] Hasheminejad, S., Mitsudharmadi, H., and Winoto, S., 2014. "Effect of flat plate leading edge pattern on structure of streamwise vortices generated in its boundary layer". Journal of Flow Control, Measurement \& Visualisation, 02(01), pp. 18-23.

[10] Hasheminejad, S., Mitsudharmadi, H., Winoto, S., Low, H. T., and Lua, K. B., 2017. "Development of streamwise counter-rotating vortices in flat plate boundary layer pre-set by leading edge patterns". Experimental Thermal and Fluid Science, 86, pp. 168-179.

[11] Weber, P., Howle, L., and Murray, M. M., 2010. "Lift, drag, and cavitation onset on rudders with leading-edge tubercles". Mar. Technol. Sname News, 47(1), pp. 27-36.

[12] Shi, W., Atlar, M., Rosli, R., Aktas, B., and Norman, R., 2016. "Cavitation observations and noise measurements of horizontal axis tidal turbines with biomimetic blade leading-edge designs". Ocean Engineering, 121, pp. 143155.

[13] Shi, W., Atlar, M., Norman, R., Aktas, B., and Turkmen, S., 2015. "Biomimetic improvement for a tidal turbine blade". In 11th European Wave and Tidal Energy Conference, pp. 110-119.

[14] Shi, W., Atlar, M., Norman, R., Aktas, B., and Turkmen, S., 2016. "Numerical optimization and experimental validation for a tidal turbine blade with leading-edge tubercles". Renewable Energy, 96, pp. 42-55.

[15] Shi, W., Atlar, M., Seo, K., Norman, R., and Rosli, R., 2016. "Numerical simulation of a tidal turbine based hydrofoil with leading-edge tubercles". In ASME 2016 35th International Conference on Ocean, Offshore and Arctic Engineering, OMAE 2016, Vol. 6, American Society of Me- chanical Engineers (ASME).

[16] Shi, W., Rosli, R., Atlar, M., Norman, R., Wang, D., and Yang, W., 2016. "Hydrodynamic performance evaluation of a tidal turbine with leading-edge tubercles". Ocean Engineering, 117, pp. 246-253.

[17] Gruber, T., Murray, M., and Fredriksson, D., 2011. "Effect of humpback whale inspired tubercles on marine tidal turbine blades". In ASME 2011 International Mechanical Engineering Congress and Exposition, American Society of Mechanical Engineering, pp. 851-857.

[18] Shi, W., Atlar, M., and Norman, R., 2017. "Detailed flow measurement of the field around tidal turbines with and without biomimetic leading-edge tubercles". Renewable Energy, 111, pp. 688-707.

[19] Shi, W., Atlar, M., Norman, R., and Seo, K. "Cfd investigations on leading-edge tubercles as applied no a tidal turbine blade”. In Grand Renewable Energy 2014.

[20] ITTC. "ITTC recommended procedures and guidelines resistance test". In 26th International Towing Tank Conference.

[21] Celik, I., Ghia, U., Roache, P., and Christopher, 2008. "Procedure for estimation and reporting of uncertainty due to discretization in CFD applications". Journal of fluids Engineering-Transactions of the ASME, 130(7).

[22] Richardson, L. F., and Glazebrook, R. T., 1911. "Ix. the approximate arithmetical solution by finite differences of physical problems involving differential equations, with an application to the stresses in a masonry dam". Philosophical Transactions of the Royal Society of London. Series A, Containing Papers of a Mathematical or Physical Character, 210(459-470), pp. 307-357. 